\title{
Unemployment and retirement and ill-health: a cross-sectional analysis across European countries
}

\author{
Seyed Mohammad Alavinia $\cdot$ Alex Burdorf
}

Received: 6 June 2006 / Accepted: 11 January 2008 / Published online: 9 February 2008

(C) The Author(s) 2008

\begin{abstract}
Objective To determine the associations between different measures of health and labor market position across ten European countries.

Methods We studied 11,462 participants of the Survey on Health and Ageing in Europe (SHARE) who were 5064 years old. Logistic regression was used to calculate the associations between health and other determinants and being retired, unemployed, or a homemaker.

Results A large variation across European countries was observed for the proportion of persons $50-65$ years with paid employment, varying among men from $42 \%$ in Austria to $75 \%$ in Sweden and among women from $22 \%$ in Italy to $69 \%$ in Sweden. Among employed workers $18 \%$ reported a poor health, whereas this proportion was $37 \%$ in retirees, $39 \%$ in unemployed persons, and $35 \%$ in homemakers. A perceived poor health was strongly associated with nonparticipating in labor force in most European countries. A lower education, being single, physical inactivity and a high body mass index were associated with withdrawal from the labor force. Long-term illnesses such as depression, stroke, diabetes, chronic lung disease, and musculoskeletal disease were significantly more common among those persons not having paid employment.

Conclusion In many European countries a poor health, chronic diseases, and lifestyle factors were associated with being out of the labor market. The results of this study suggest that in social policies to encourage employment among
\end{abstract}

S. M. Alavinia · A. Burdorf $(\bowtie)$

Department of Public Health, Erasmus MC,

University Medical Center Rotterdam,

P.O. Box 2040, 3000 CA Rotterdam, The Netherlands

e-mail: a.burdorf@erasmusmc.nl older persons the role of ill-health and its influencing factors needs to be incorporated.

Keywords Self-perceived health · Unemployment · Retirement $\cdot$ Lifestyle $\cdot$ Chronic disease

\section{Introduction}

In many countries throughout the industrial world the population is ageing; this is largely caused by the increasing life expectancy (Ilmarinen 2001). Despite an increased life expectancy, improved living conditions, and better health status, the average time people spend in paid work has decreased in most European countries. This rather paradoxical development is partly due to a delay of young people entering the labor market. However, even more important is that older workers are exiting the labor market in great numbers (Stattin 2005). Thus, many countries are developing policies to encourage older worker to remain active in the labor market and delay retirement (Cai et al. 2006). Clearly, the success of these policies will depend on a better understanding of aging in the workforce and the particular role of health in continuing work or withdrawal from the labor market.

There is ample evidence on the relation between unemployment and ill-health, showing that unemployment may affect people's health but also that health may determine the selection into and out of the workforce (Bartley 1994). A prospective study among construction workers demonstrated that several health problems, especially stress symptoms and mental disorders, predicted the risk of long-term unemployment. However, this study also pointed at the importance of socio-demographic variables, such as education and sex, and lifestyle factors, such as alcohol consumption 
and obesity, that may modify the effect of health (LeinoArjas et al. 1999). Unemployment is only one mechanism of withdrawal from the labor force among elderly workers, since workers may leave the workforce due to disability, unemployment, or early retirement, partly depending on eligibility criteria and generosity of disability and retirement benefits (Stattin 2005). Several studies have demonstrated that health problems, such as perceived poor health or presence of a chronic disorder, contribute to an early exit from work (Cai et al. 2006; Monden 2005). Although early retirement is regarded as a voluntary withdrawal from the labor market, it has been shown among Finnish workers that during an 11-year follow-up a poor health predicted early retirement through both illness-based and non-illnessbased early pension schemes (Karpansalo et al. 2004). Thus, it is important to investigate whether the associations between health and non-participation in the workforce are similar across different routes of withdrawal from the labor force and what the effects are of socio-demographic characteristics and other determinants of health.

In this paper we examined the health status among men and women in the age group 50-64 years according to their labor market position. The aims of this study were to describe associations between perceived health and specific diseases with being unemployed, retired, or taking care of household and to analyze whether the observed associations of health with labor market position differed across countries in Europe.

\section{Materials and methods}

\section{Study population}

The subjects were participants of the Survey on Health and Ageing in Europe (SHARE study). Survey on Health and Ageing in Europe is a longitudinal survey that aims to collect medical, social, and economic data on the population aged over 50 in ten European Union countries (Sweden, Denmark, The Netherlands, Germany, Austria, Switzerland, France, Italy, Spain, and Greece) (Borsch-Supan et al. 2005a; Borsch-Supan et al. 2005b). In the participating SHARE countries the institutional conditions with respect to sampling were so different that a uniform sampling design for the entire project was not feasible. Different registries of national or local level were used that permitted stratification by age. The sampling designs varied from simple random selection of households to complicated multistage designs. The first wave of data was collected by interviews between April and October 2004. The overall household response across the ten SHARE countries in which data collection took place in 2004 was $61.8 \%$, although substantial differences among countries were observed (Borsch-Supan et al. 2005b). From the collected 22,177 individuals, we investigated 11,462 subjects who were between $50-65$ years old. We excluded those individuals over age 65 , since we have assumed workers normally retire when they become 65 years old. While this assumption has certainly limitations, given the complexity to define retirement at individual level, it was regarded as the best available definition to facilitate cross-national comparisons.

\section{Labor force participation}

The outcome of this study is work status, which was based on self-reported current economic status with six mutually exclusive categories: paid work, retired, unemployed, disabled, homemaker, or others. The definition of being employed in SHARE encompasses all individual who declared to have done any kind of paid work in the last four weeks, including self-employed work for family business. Unemployed were those who were laid off from their last job before being able to benefit from normal pension benefits, and therefore were forced to spend some time in unemployment before effectively being retired. Sickness or disability insurance applied to people who exited the labor force for reasons of recognized health problems (BorschSupan et al. 2005a). We excluded the disabled participants, because this category predominantly includes persons whose health problems at work were an eligibility criterion for receiving a disability pension.

\section{Health measurement}

The European version of self-perceived health, a 5-point scale question ranging between very good to poor, was used to define participant with a poor health (less than good). This frequently used question has been shown to be a good indicator for general physical health (Dwyer et al. 1999; Idler et al. 1997). A second general health measure was long-term illness. Survey on Health and Ageing in Europe has asked respondents whether they had a chronic disease diagnosed by a doctor in their lifetime and those with a positive answer were asked to report the disease from a limitative list. The questionnaire also included the EURO-D scale for depression diagnosis, which has been validated in an earlier cross-European study on depression (Copeland et al. 1999). The EURO-D scale of depression takes into account the following 12 items: depression, pessimism, suicidal, guilt, sleep, interest, irritability, appetite, fatigue, concentration, enjoyment, and tearfulness. A sum score over dichotomous answers was calculated, varying from 0 (not depressed) to 12 (very depressed). For the purpose of this study we defined a clinically significant depression as a EURO-D score greater than three (Borsch-Supan 
et al. 2005a). In the analysis we used tertile cut-off points with a score from 0 to 3 as reference group, a score of 4-8 as moderately depressed, and a score from 9 to 12 as heavily depressed.

\section{Individual characteristics}

Education was coded according to the 1997 International Standard Classification of Education (ISCED-97) and categorized as low (pre-primary, primary and lower secondary education), intermediate (upper secondary education) and high (post secondary education). Body mass index (BMI) was calculated by dividing body weight in kilogram by the square of body height in meters. According to the BMI, we defined persons as normal (BMI below 25), overweight (BMI from 25 to 30), or obese (BMI above 30). Marital status was used to categorize individuals into those who had a partner and those without. Smokers were subjects who were currently smoking; all others were categorized as nonsmokers. Problematic drinking was defined by alcohol consumption of two or more glasses of alcoholic beverage at least 5 days a week in last 6 months (Health Council of the Netherlands 2006). Physical activity was used to categorize individuals with vigorous or moderate physical activity and those without, in compliance with the guidelines for physical activity in leisure time (Pate et al. 1995).

\section{Statistical analysis}

Logistic regression analysis was used to calculate the association between several determinants and the occurrence of early retirement, unemployment, and homemaker. The Odds Ratio was estimated as the measure of association. For the initial selection of potential variables to be included in the multivariate models, univariate associations were determined and variables with a significance level of $P<0.10$ were considered for further analysis. In the final multivariate models for each category of labor force withdrawal variables were only included when statistically significant $(P<0.05)$ with either early retirement, unemployment, or homemaker.

In the first step self-perceived poor health and presence of long-term illness were investigated with adjustment for sex, age, country, education, and marital status as potential confounders. In the second step different chronic diseases were investigated as determinants of early retirement and unemployment, while adjusting for self-perceived health and other potential confounders. Finally, adjusted odds ratios for perceived poor health with retirement and unemployment were calculated within each country, with adjustment for significant lifestyle and sociodemographic variables. Since the number of male subjects was too small in the category homemakers (i.e. taking care of a house- hold), the analysis on the association between health and homemaker was performed only in women.

In order to investigate the influence of national labor market conditions, the Pearson correlation coefficient was used to analyze the association between unemployment rates at national level and observed odds ratios for health with early retirement, unemployment, and being homemaker. The statistical analyses were carried out with SPSS version 11.0 for Windows.

\section{Results}

Table 1 shows the distribution of the respondents according to employment status within each country, stratified by sex. The proportion of retired people in the age class 50-64 years differed strongly among European countries, ranging from $8.4 \%$ in The Netherlands to $47.8 \%$ in Austria. Unemployment ranged from $2.7 \%$ in Greece to $9.3 \%$ in Germany. The proportion of homemakers among men was extremely small in all countries. Sweden has the lowest and Spain has the highest proportion of homemaker's women (2.1 and $48.0 \%$ respectively). In some countries there was very little difference in labor force participation between men and women, such as Sweden and Denmark, whereas in other countries labor force participation among women was very low, notably in Greece and Spain.

Among employed workers $18.3 \%$ reported a poor health, whereas this proportion was $37.2 \%$ in retired workers, $38.9 \%$ in unemployed workers, and $35.1 \%$ in homemakers. A perceived poor health was strongly associated with nonparticipation in labor force (Table 2). Long-term illness was present among $36.1 \%$ of employed workers, $48.0 \%$ of unemployed workers, $50.1 \%$ of retired workers, and $44.1 \%$ of homemakers, and was significantly associated with unemployment. Lower and intermediate levels of education were significantly associated with all three mechanism of labor force exit. Having a partner was inversely associated with early retirement and unemployment, whereas it showed a direct significant association with being homemaker. Several lifestyle factors had an effect on non-participation in the work force, most notably lack of physical activity and obesity.

Table 3 shows that depression was the most important health problem associated with all three types of labor force exit. Among other specific chronic diseases, stroke was strongly associated with early retirement, and diabetes was significantly related to early retirement and staying at home as homemaker. In each of these models, the odds ratio for poor health was very similar to its value presented in table 2. In addition, when the chronic diseases were adjusted for each other, the results remained almost the same. 
Table 1 Distribution (\%) of persons aged 50-64 years, stratified by sex and country, over employment, retirement, and homemaker among ten European countries in the study population of the SHARE-study
Table 2 Multivariate associations of poor health and long-term illness with early retirement, unemployment, and homemaker, adjusted for country, socio-demographic characteristics, and lifestyle factors
$O R$ odds ratio, $C I$ confidence interval

$* P<0.05$

a Only in women

\begin{tabular}{|c|c|c|c|c|c|c|c|c|c|}
\hline \multirow[t]{2}{*}{ Country } & \multirow[t]{2}{*}{$N$} & \multicolumn{2}{|c|}{ Employed } & \multicolumn{2}{|c|}{ Unemployed } & \multicolumn{2}{|c|}{ Retired } & \multicolumn{2}{|c|}{ Homemaker } \\
\hline & & Male & Female & Male & Female & Male & Female & Male & Female \\
\hline Sweden & 1,582 & 75.4 & 69.5 & 4.6 & 3.3 & 13.7 & 17.2 & 0.0 & 2.1 \\
\hline Denmark & 909 & 67.0 & 57.9 & 7.8 & 6.9 & 20.0 & 25.1 & 0.2 & 2.4 \\
\hline The Netherlands & 1,682 & 60.6 & 37.9 & 4.1 & 2.3 & 14.4 & 3.2 & 0.8 & 43.3 \\
\hline Germany & 1,545 & 59.2 & 45.8 & 11.1 & 7.8 & 21.4 & 18.8 & 0.4 & 21.3 \\
\hline Austria & 984 & 41.6 & 23.8 & 5.0 & 3.8 & 46.5 & 48.8 & 0.5 & 19.7 \\
\hline Switzerland & 500 & 77.8 & 58.0 & 2.9 & 3.1 & 9.9 & 8.9 & 1.2 & 21.8 \\
\hline France & 886 & 56.1 & 50.7 & 6.3 & 7.2 & 30.1 & 16.6 & 1.2 & 19.3 \\
\hline Italy & 1,308 & 44.0 & 22.4 & 5.0 & 1.6 & 48.1 & 28.8 & 0.2 & 45.0 \\
\hline Spain & 1,043 & 59.0 & 28.8 & 6.7 & 6.3 & 22.0 & 4.3 & 0.7 & 53.9 \\
\hline Greece & 1,023 & 69.8 & 28.6 & 3.0 & 2.4 & 25.2 & 20.2 & 0.4 & 48.0 \\
\hline
\end{tabular}

\begin{tabular}{|c|c|c|c|c|}
\hline & $N$ & $\begin{array}{l}\text { Retired } \\
(n=2,460)\end{array}$ & $\begin{array}{l}\text { Unemployed } \\
(n=579)\end{array}$ & $\begin{array}{l}\text { Homemaker } \\
(n=1,799)^{\mathrm{a}}\end{array}$ \\
\hline & & OR $(95 \% \mathrm{CI})$ & OR $(95 \% \mathrm{CI})$ & OR $(95 \% \mathrm{CI})$ \\
\hline Perceived poor health & 3,385 & $1.99 *(1.72-2.29)$ & $2.14 *(1.75-2.62)$ & $1.69 *(1.43-1.99)$ \\
\hline Long-term illness & 4,906 & $1.09(0.97-1.24)$ & $1.34 *(1.11-1.62)$ & $0.92(0.80-1.07)$ \\
\hline Female & 6,231 & $1.30 *(1.14-1.47)$ & $1.15(0.95-1.38)$ & - \\
\hline \multicolumn{5}{|l|}{ Age (years) } \\
\hline $50-54$ & 3,796 & 1.00 & 1.00 & 1.00 \\
\hline $55-59$ & 3934 & $3.85 *(3.19-4.66)$ & $1.22(0.99-1.49)$ & $1.54 *(1.32-1.81)$ \\
\hline $60-64$ & 3,759 & $29.98 *(24.92-36.05)$ & $1.83 *(1.45-2.32)$ & $3.52 *(2.93-4.23)$ \\
\hline \multicolumn{5}{|l|}{ Education } \\
\hline Low & 4,771 & $1.88 *(1.61-2.19)$ & $1.69 *(1.33-2.15)$ & $4.90 *(4.06-5.92)$ \\
\hline Middle & 3,684 & $1.91 *(1.63-2.23)$ & $1.68 *(1.33-2.13)$ & $2.18 *(1.78-2.66)$ \\
\hline High & 2,904 & 1.00 & 1.00 & 1.00 \\
\hline Without partner & 2,176 & $1.32 *(1.13-1.53)$ & $1.93 *(1.58-2.36)$ & $0.38 *(0.31-0.46)$ \\
\hline \multicolumn{5}{|l|}{ BMI } \\
\hline$<24.9 \mathrm{~kg} / \mathrm{m}^{2}$ & 4,458 & 1.00 & 1.00 & 1.00 \\
\hline $29.9 \mathrm{~kg} / \mathrm{m}^{2}$ & 4,844 & $1.15^{*}(1.00-1.31)$ & $1.05(0.86-1.29)$ & $1.23 *(1.05-1.43)$ \\
\hline$\geq 30 \mathrm{~kg} / \mathrm{m}^{2}$ & 1,947 & $1.43 *(1.20-1.70)$ & $1.31 *(1.01-1.68)$ & $1.34 *(1.10-1.64)$ \\
\hline Current smoking & 3,040 & $1.12(0.98-1.29)$ & $1.69 *(1.40-2.04)$ & $0.840 .71-1.00)$ \\
\hline Current drinking & 1,593 & $1.36 *(1.16-1.61)$ & $1.34 *(1.05-1.71)$ & $1.06(0.81-1.38)$ \\
\hline No physical activity & 598 & $2.05 *(1.52-2.74)$ & $1.43(0.92-2.23)$ & $1.97 *(1.39-2.79)$ \\
\hline
\end{tabular}

Table 4 shows that self-perceived poor health was significantly associated with early retirement in seven out of ten European countries, with unemployment in six out of ten countries, and with being homemaker (only among women) in three out of ten countries. Similar associations were observed for the presence of a long-term illness and retirement and unemployment (results not shown). France was the only country where a perceived poor health was not associated with work status. In most countries a similar effect of unemployment and retirement on perceived poor health was observed, except for Sweden where a poor health was strongly associated with early retirement, but not associated with unemployment. The unemployment rate at national level was moderately, but not statistically significant, associated with the magnitude of the odds ratio for poor health and unemployment (Pearson correlation coefficient 0.3 ).

\section{Discussion}

In this study we observed that a self-perceived poor health was associated with non-participation in the labor force due to early retirement, being unemployed, or being a homemaker. We also found that, independent from self-perceived poor health, depression, stroke, diabetes, and 
Table 3 Multivariate associations between specific chronic diseases and retirement, unemployment, and homemaker, adjusted for self-perceived health, country, socio-demographic characteristics, and lifestyle factors

\begin{tabular}{|c|c|c|c|c|}
\hline Self-reported chronic disease & $N$ & $\begin{array}{l}\text { Retired } \\
\text { OR }(95 \% \mathrm{CI})\end{array}$ & $\begin{array}{l}\text { Unemployed } \\
\text { OR }(95 \% \mathrm{CI})\end{array}$ & $\begin{array}{l}\text { Homemaker } \\
\text { OR }(95 \% \mathrm{CI})\end{array}$ \\
\hline Heart attack & 720 & $1.17(0.93-1.49)$ & $0.96(0.66-1.40)$ & $1.20(0.83-1.75)$ \\
\hline Hypertension & 2,846 & $1.05(0.92-1.21)$ & $0.92(0.74-1.15)$ & $1.11(0.94-1.31)$ \\
\hline Stroke & 234 & $2.60 *(1.66-4.07)$ & $1.11(0.53-2.32)$ & $1.27(0.65-2.47)$ \\
\hline Diabetes & 799 & $1.33 *(1.05-1.68)$ & $1.38(0.99-1.93)$ & $1.57 *(1.14-2.17)$ \\
\hline Chronic lung disease and asthma & 823 & $1.21(0.96-1.52)$ & $0.96(0.68-1.34)$ & $0.80(0.60-1.06)$ \\
\hline Arthritis and osteoporosis & 1,986 & $1.39 *(1.18-1.65)$ & $1.12(0.87-1.44)$ & $1.44 *(1.20-1.72)$ \\
\hline Not depressed & 8,952 & 1.00 & 1.00 & 1.00 \\
\hline Moderately depressed & 2,230 & $1.28 *(1.08-1.52)$ & $1.45 *(1.15-1.82)$ & $1.24 *(1.05-1.47)$ \\
\hline Heavily depressed & 164 & $2.60 *(1.37-4.94)$ & $3.03 *(1.53-6.21)$ & $2.42 *(1.23-4.73)$ \\
\hline
\end{tabular}

$O R$ odds ratio, $C I$ confidence interval

$* P<0.05$, adjusted for self-perceived health, sex, age, education, body mass index, marital status, smoking, drinking, and physical activity

a Only in women

Table 4 Multivariate associations between poor health and early retirement, unemployment, and homemaker within ten European countries, adjusted for socio-demographic characteristics and lifestyle factors

$O R$ odds ratio, $C I$ confidence interval

$* P<0.05$, adjusted for self-perceived health, sex, age, education, body mass index, marital status, smoking, drinking, and physical activity

a Only in women

\begin{tabular}{llll}
\hline Country & $\begin{array}{l}\text { Retired OR } \\
(95 \% \mathrm{CI})\end{array}$ & $\begin{array}{l}\text { Unemployment } \\
\text { OR }(95 \% \mathrm{CI})\end{array}$ & $\begin{array}{l}\text { Homemaker } \\
\text { OR }(95 \% \mathrm{CI})\end{array}$ \\
\hline Sweden & $4.16^{*}(2.97-5.81)$ & $1.07(0.57-2.00)$ & $1.38(0.46-4.16)$ \\
Denmark & $4.40^{*}(2.62-7.52)$ & $2.48^{*}(1.31-4.68)$ & $0.41(0.4-4.00)$ \\
The Netherlands & $1.33(0.71-2.48)$ & $2.82^{*}(1.50-5.30)$ & $1.45(0.94-2.25)$ \\
Germany & $2.46^{*}(1.60-3.76)$ & $2.55^{*}(1.68-3.86)$ & $1.89 *(1.18-3.02)$ \\
Austria & $1.67 *(1.00-2.80)$ & $1.48(0.63-3.47)$ & $1.38(0.61-3.13)$ \\
Switzerland & $1.64(0.56-4.79)$ & $3.99 *(1.05-15.11)$ & $0.66(0.20-2.18)$ \\
France & $1.07(0.56-2.03)$ & $1.20(0.60-2.39)$ & $1.18(0.59-2.34)$ \\
Italy & $1.45^{*}(1.00-2.10)$ & $3.77 *(1.78-8.01)$ & $1.48(0.90-2.43)$ \\
Spain & $2.00^{*}(1.19-3.36)$ & $2.05 *(1.08-3.92)$ & $2.39 *(1.42-4.02)$ \\
Greece & $2.21 *(1.38-3.56)$ & $1.81(0.67-4.91)$ & $2.05 *(1.15-3.68)$ \\
\hline
\end{tabular}

musculoskeletal diseases were strongly related to these different categories of labor force exit. Obesity and physical inactivity had statistically significant associations with any type of quitting work. These associations were consistently observed in most European countries, except in France.

Some limitation must be taken into account in this study. The first limitation of the study is the household response of $61.8 \%$ with an additional response of $86.3 \%$ for members within a household. Since non-response bias depends on how much respondents and non-respondents differ with respect to the variables of interest, bias due to non-response could not be ruled out in our study. However, the overall response of SHARE was comparable with the response of two official Europe-wide surveys (The European Community Household Panel (ECHP), and the European labor force survey (EU-LFP)), but it was substantially higher than the response achieved by other cross-sectional communitybased surveys on work and health in Europe (Borsch-Supan et al. 2005b). Secondly, within each country we did not have enough power to investigate the associations between illhealth and different mechanisms of labor force exit. Although the proportion of persons with a self-perceived poor health differed strongly among countries, similar associations with unemployment and retirement were observed within each country. Finally, the cross-sectional data used in this paper do not permit further explanation whether poor health determines labor force exit, or poor health is a consequence of becoming unemployed or retired. Previous studies have shown that both mechanisms are probably true (Bartley 1994; Bartley et al. 2004; Thomas et al. 2005). It has been suggested that stress due to loss of income and general lack of activity in non-participation may lead to deterioration in health (Morrell et al. 1994; Graetz 1993; Mathers et al. 1998). On the other hand, according to the healthy worker effect subjects with ill health and chronically disabled subjects have less chance to be selected into employment and, vice versa, workers in poor health are more likely to drop out of work (Thomas et al. 2005). 
In this study we found that self-perceived poor health was associated with early retirement, being unemployed, or (only among women) being a homemaker. After adjustment for various lifestyles and sociodemographic factors and presence of several chronic diseases, the observed associations remained remarkably stable with very similar odds ratios. Several studies have shown that self-perceived poor health influences the probability of entering the labor force and also predicts the risk of early retirement (Cai et al. 2006; Karpansalo et al. 2004). On the other hand, poor health has also been reported as a consequence of becoming unemployed (Bartley et al. 2004; Murphy et al. 1999). Among workers aged 51-61 years, at 2-year follow-up a recurrence of job loss was associated with increased risk of clinically relevant depressive symptoms (Gallo et al. 2006).

Having a disease often negatively affects the capacity to participate in labor force. Depression, stroke, diabetes, and musculoskeletal diseases were associated with different types of non-participation in the labor force. This may be true for other diseases as well, but their prevalence was too low to demonstrate an effect on work status. The question of interest is whether maintaining labor force participation is a problem for chronically ill individuals, or whether there is less probability for chronically ill patients to start participating in work. It has been shown that depression, even in childhood, might lead to an early retirement and labor force exit (Karpansalo et al. 2005). Gaining insight into the effect of chronic diseases on labor force participation may be helpful to determine policy measures that are required to improve labor participation among chronically ill or disabled individuals.

There is a growing concern about the relationship between health-related behaviors and employment status. In this cross-sectional study certain lifestyle factors, most notably obesity and lack of physical activity, were associated with labor force termination. Obese individuals have reported a poor work ability more often than those of normal weight individuals (Laitinen et al. 2005). Obesity also had a negative impact on self-perceived health among adults (Okosun et al. 2001). A longitudinal study showed that neither overweight nor obesity at the age of 14 years predicted unemployment. However, the authors mentioned that adolescent obesity appears to affect the risk of unemployment through its association with low level of education (Laitinen et al. 2002). We observed that physical inactivity was significantly associated with being out of the labor force. One study has shown that vigorous exercise during leisure time was statistically associated with improvement in work ability (Tuomi et al. 1997). This observation and the highest proportion of physical inactive persons among those not in the labor force is of particular interest and has implications on policies and programs aiming at promoting healthy ageing. It is suggested that in order to prevent labor force exit attention should be paid to the combined effect of lifestyle and sociodemographic factors on diseases and ill-health.

In ten European countries, except in France, self-perceived poor health was associated with being unemployed, retired, or taking care of a household. Sweden was the only country where retired persons more often had a poor health, but no difference was observed between those employed and unemployed or between those employed and homemakers. A possible explanation is that the active labor policies and employment protection in Sweden increase the opportunities for people with chronic illness to remain in work (Burstrom et al. 2000).

In conclusion, in many European countries a self-perceived poor health was associated with early retirement, unemployment, and among women being a homemaker. Some chronic diseases such as stroke, depression, diabetes, chronic lung disease, and musculoskeletal diseases were more prevalent among unemployed and retired persons than in workers with paid employment. Similar associations were observed for certain lifestyle factors, such as a high body mass index and lack of physical activity. The results of this study have important policy implications for healthy and successful ageing. It is suggested that in social policies to encourage employment among older persons the role of ill-health and its influencing factors needs to be incorporated.

Acknowledgments This paper uses data from the early release 1 of SHARE 2004. This release is preliminary and may contain errors that will be corrected in later releases. The SHARE data collection has been primarily funded by the European Commission through the 5 th framework programme (project QLK6-CT-2001-00360 in the thematic programme quality of life). Additional funding came from the US National Institute on Aging (U01 AG09740-13S2, P01 AG005842, P01 AG08291, P30 AG12815, Y1-AG-4553-01 and OGHA 04-064). Data collection in Austria (through the Austrian Science Fund, FWF), Belgium (through the Belgian Science Policy Office) and Switzerland (through the BBW/OFES/UFES) was nationally funded.

Open Access This article is distributed under the terms of the Creative Commons Attribution Noncommercial License which permits any noncommercial use, distribution, and reproduction in any medium, provided the original author(s) and source are credited.

\section{References}

Bartley M (1994) Unemployment and ill health: understanding the relationship. J Epidemiol Community Health 48:333-337

Bartley M, Sacker A, Clarke P (2004) Employment status, employment conditions, and limiting illness: prospective evidence from the British household panel survey 1991-2001. J Epidemiol Community Health 58:501-506

Borsch-Supan A, Jurges H, Mackenbach J, Siegrist J, Weber G (2005a) Health, ageing and retirement in Europe. First results from the survey of health, ageing and retirement in Europe. Mannheim Research Institute for the Economic of Ageing (MEA) 
Borsch-Supan A, Kartsen H, Jurges H (2005b) A new comprehensive and international view on ageing: introducing the 'Survey of Health, Ageing and Retirement in Europe'. Eur J Ageing 2:245-253

Burstrom B, Whitehead M, Lindholm C, Diderichsen F (2000) Inequality in the social consequences of illness: how well do people with long-term illness fare in the British and Swedish labor markets? Int J Health Serv 30:435-451

Cai L, Kalb G (2006) Health status and labor force participation: evidence from Australia. Health Econ 15:241-261

Copeland JR, Beekman AT, Dewey ME, Hooijer C, Jordan A, Lawlor BA et al (1999) Depression in Europe. Geographical distribution among older people. Br J Psychiatry 174:312-321

Dwyer DS, Mitchell OS (1999) Health problems as determinants of retirement: are self-rated measures endogenous? J Health Econ 18:173-193

Gallo WT, Bradley EH, Teng HM, Kasl SV (2006) The effect of recurrent involuntary job loss on the depressive symptoms of older US workers. Int Arch Occup Environ Health 80:109-116

Graetz B (1993) Health consequences of employment and unemployment: longitudinal evidence for young men and women. Soc Sci Med 36:715-724

Health Council of the Netherlands (2006) Guidelines for a healthy diet 2006. The Hague: Health Council of the Netherlands, publication no. $1006 / 21$

Idler EL, Benyamini Y (1997) Self-rated health and mortality: a review of twenty-seven community studies. J Health Soc Behav 38:21-37

Ilmarinen JE (2001) Aging workers. Occup Environ Med 58:546-552

Karpansalo M, Kauhanen J, Lakka TA, Manninen P, Kaplan GA, Salonen JT (2005) Depression and early retirement: prospective population based study in middle aged men. J Epidemiol Community Health 59:70-74

Karpansalo M, Manninen P, Kauhanen J, Lakka TA, Salonen JT (2004) Perceived health as a predictor of early retirement. Scand J Work Environ Health 30:287-292
Laitinen J, Nayha S, Kujala V (2005) Body mass index and weight change from adolescence into adulthood, waist-to-hip ratio and perceived work ability among young adults. Int J Obes 29:697-702

Laitinen J, Power C, Ek E, Sovio U, Jarvelin MR (2002) Unemployment and obesity among young adults in a northern Finland 1966 birth cohort. Int J Obes Relat Metab Disord 26:1329-1338

Leino-Arjas P, Liira J, Mutanen P, Malmivaara A, Matikainen E (1999) Predictors and consequences of unemployment among construction workers: prospective cohort study. BMJ 319:600-605

Mathers CD, Schofield DJ (1998) The health consequences of unemployment: the evidence. Med J Aust 168:178-182

Monden CW (2005) Changing social variations in self-assessed health in times of transition. The Baltic States 1994-1999. Eur J Public Health 15:498-503

Morrell S, Taylor R, Quine S, Kerr C, Western J (1994) A cohort study of unemployment as a cause of psychological disturbance in Australian youth. Soc Sci Med 38:1553-1564

Murphy GC, Athanasou JA (1999) The effect of unemployment on mental health. J Occup Organ Psychol 72:83-99

Okosun IS, Choi S, Matamoros T, Dever GE (2001) Obesity is associated with reduced self-rated general health status: evidence from a representative sample of white, black, and Hispanic Americans. Prev Med 32:429-436

Pate RR, Pratt M, Blair SN, Haskell WL, Macera CA, Bouchard C et al (1995) Physical activity and public health. A recommendation from the Centers for Disease Control and Prevention and the American College of Sports Medicine. JAMA 273:402-407

Stattin M (2005) Retirement on grounds of ill health. Occup Environ Med 62:135-140

Thomas C, Benzeval M, Stansfeld SA (2005) Employment transitions and mental health: an analysis from the British household panel survey. J Epidemiol Community Health 59:243-249

Tuomi K, Ilmarinen J, Martikainen R, Aalto L, Klockars M (1997) Aging, work, life-style and work ability among Finnish municipal workers in 1981-1992. Scand J Work Environ Health 23(Suppl 1):58-65 